\begin{tabular}{|c|c|}
\hline 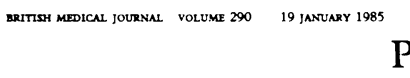 & RACTICE OBSERVED \\
\hline \multicolumn{2}{|l|}{ Practice Research } \\
\hline \multicolumn{2}{|c|}{$\begin{array}{l}\text { Why patient participation groups stop functioning: general } \\
\text { practitioners' viewpoint }\end{array}$} \\
\hline RICHARD G MANN & \\
\hline 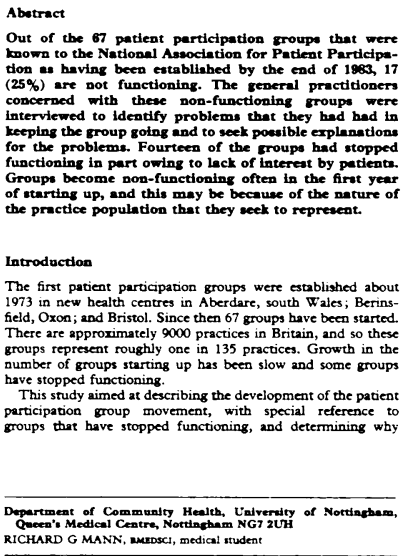 & 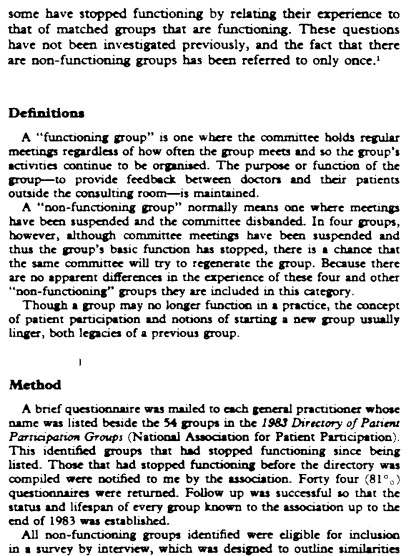 \\
\hline
\end{tabular}

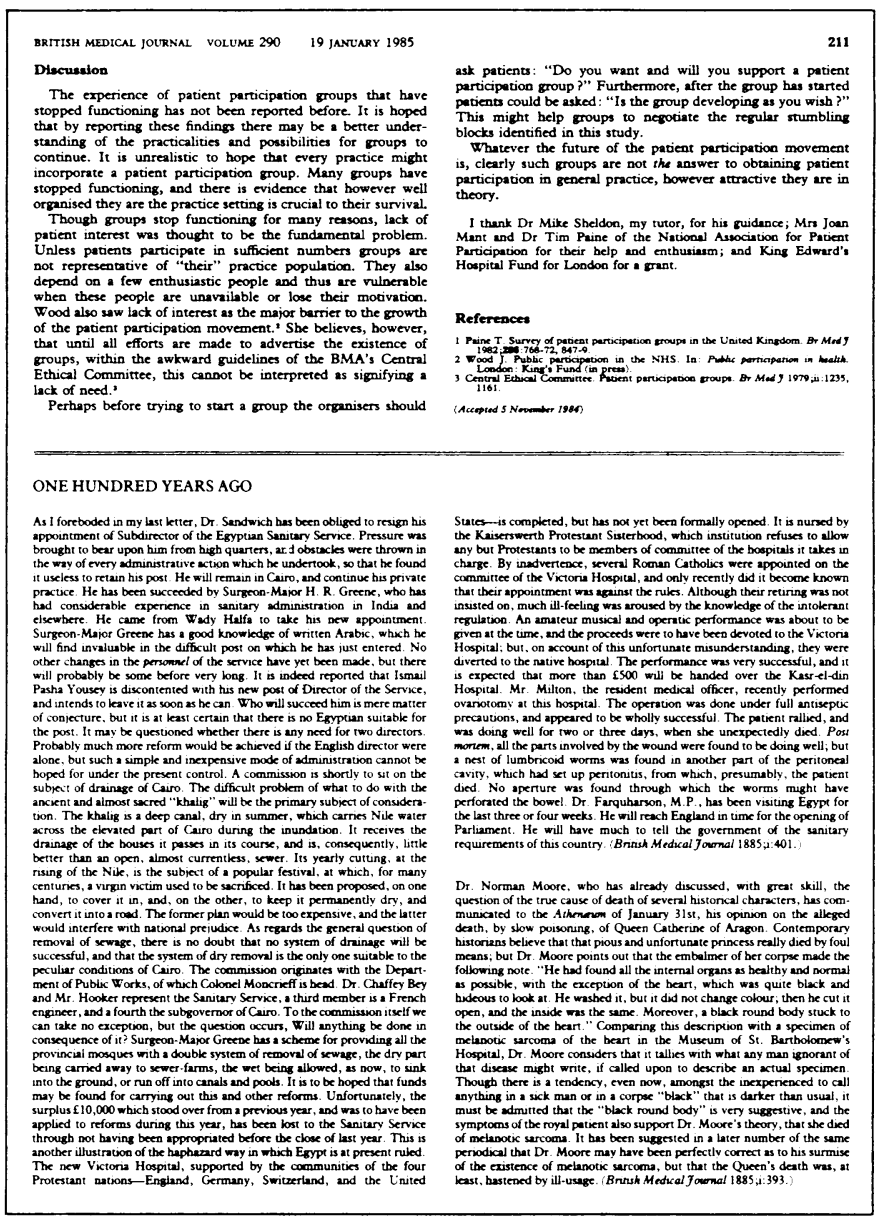

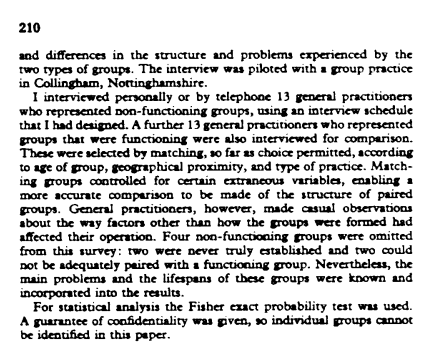

Resulte

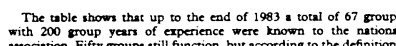

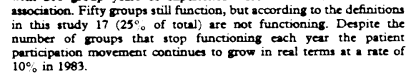

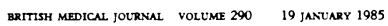

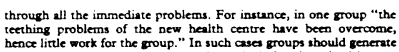

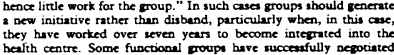

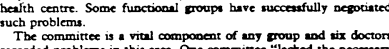

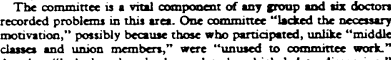

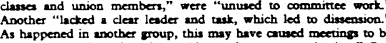

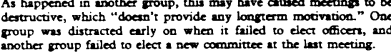

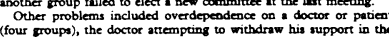

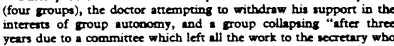

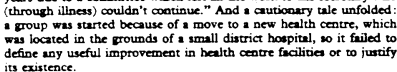

(a)

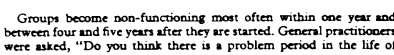

\begin{tabular}{|c|c|c|c|c|c|c|c|c|c|c|c|c|}
\hline & 1972 & 1003 & 1984 & 1003 & 1996 & 197 & 1978 & 1900 & 1000 & 101 & 1002 & 1003 \\
\hline 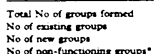 & & $\begin{array}{l}l_{0}^{2} \\
\end{array}$ & & $\vdots$ & ? & $\begin{array}{l}13 \\
: 3 \\
\vdots\end{array}$ & $\begin{array}{c}\substack{23 \\
12 \\
10 \\
0} \\
0\end{array}$ & $\begin{array}{c}x \\
\substack{x \\
0 \\
0 \\
0}\end{array}$ & $\begin{array}{c}37 \\
\frac{3}{3} \\
2\end{array}$ & 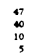 & 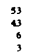 & 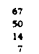 \\
\hline
\end{tabular}

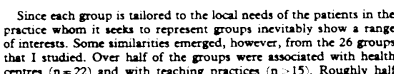

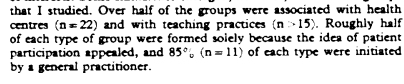

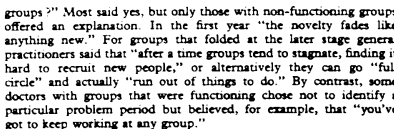

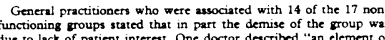

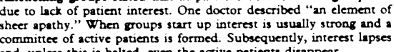

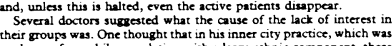

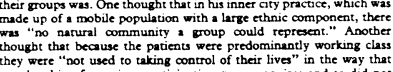

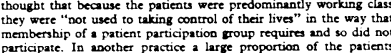

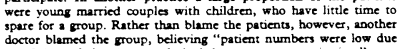

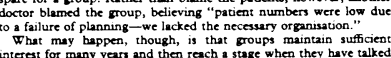

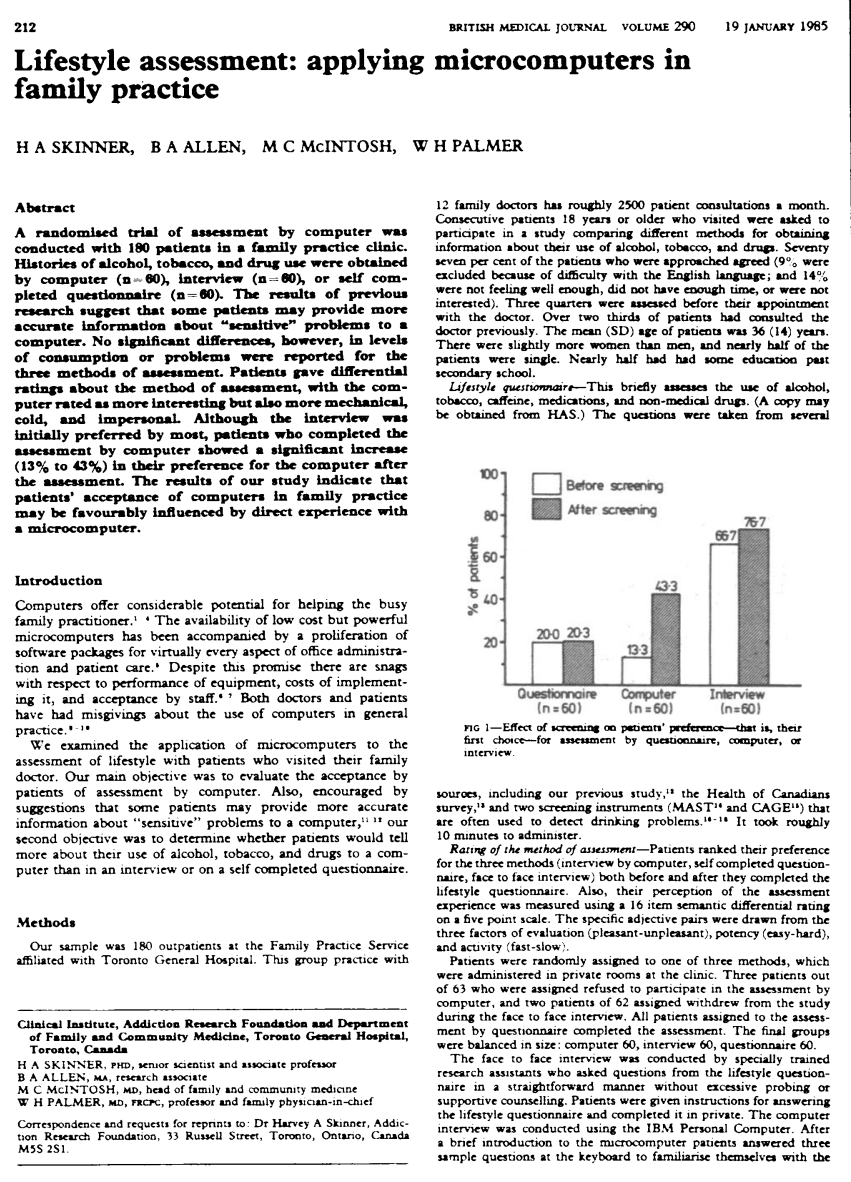




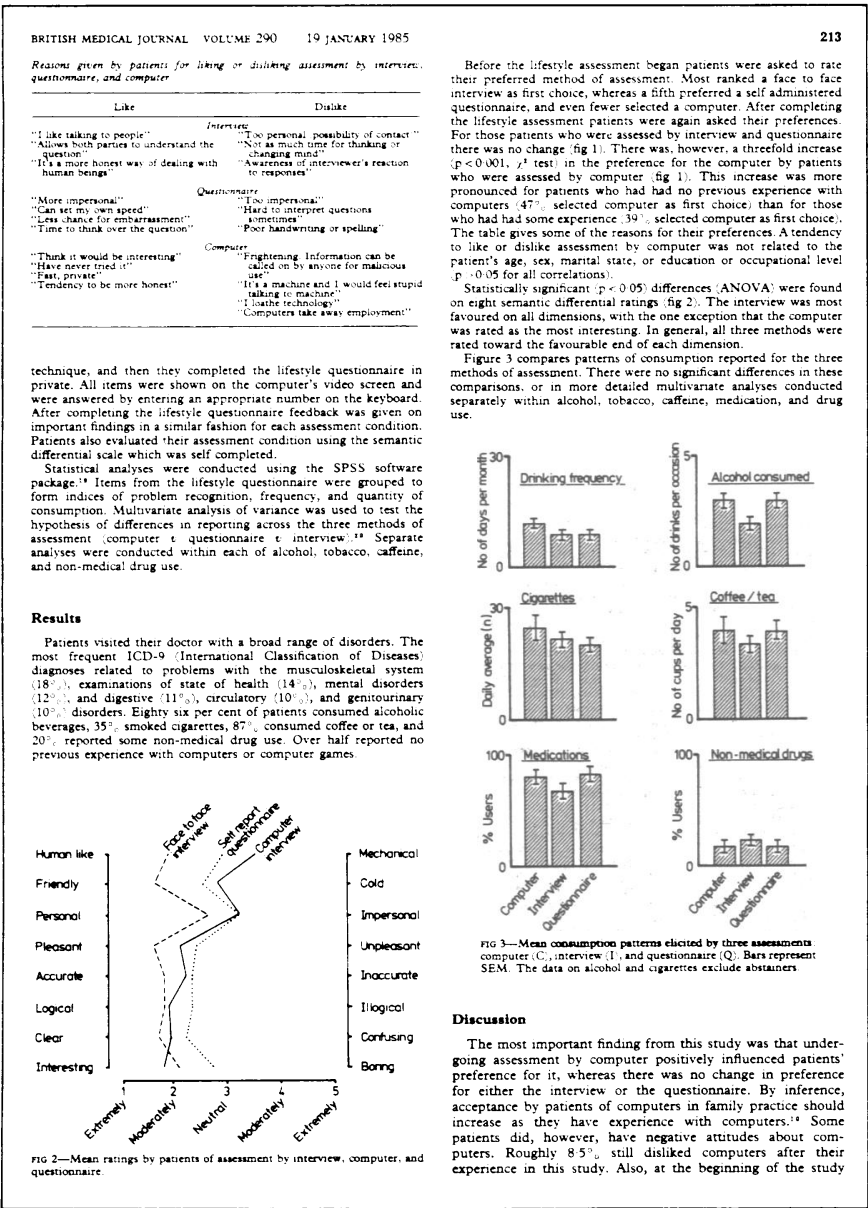

\section{Lifestyle assessment: just asking makes a difference}

H A SKINNER, B A ALLEN, M C MCINTOSH, W H PALMER

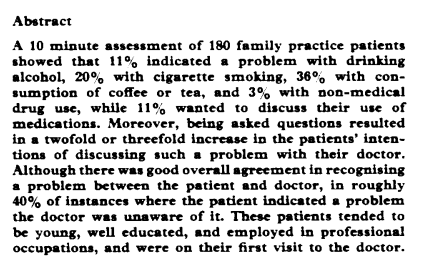

Such brief assessments of lifestyle should be routinely
conducted in family practice for both case finding and

Excessive alcohol consumption, cigarette smoking, and drug abuse are maior health concerns in W'estern sociery and often pass unrecognised in hospitals and family practice.
family doctor is in a good position to identify abuse when brief intervention may be effective." P Practical methods are needed
to ensure that histories of use are routinely taken and that diagnostic tests are applied when approprnate.
Wie evaluated the impact of assessing lifestyle on patients who visited their family doctor. Our obiectives were: (a) to
describe the extent of alcohol, tobacco, cafteine, and drug use among patients in family practice; (b) to determine whethe
routine assessment would increase the patients' intentions of
discussing a problem of abuse with their doctor; and (c) to

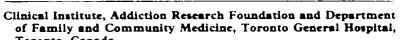

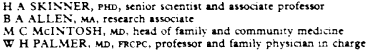

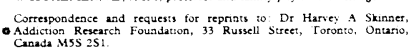

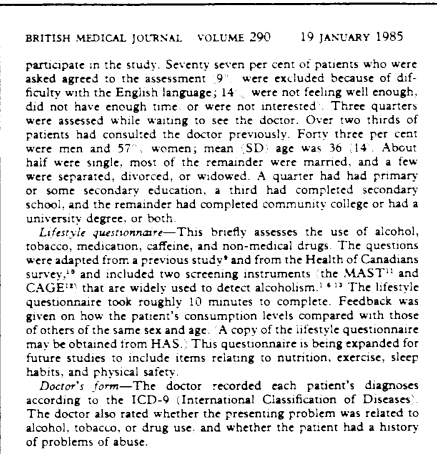

Results

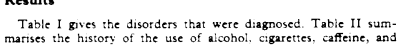
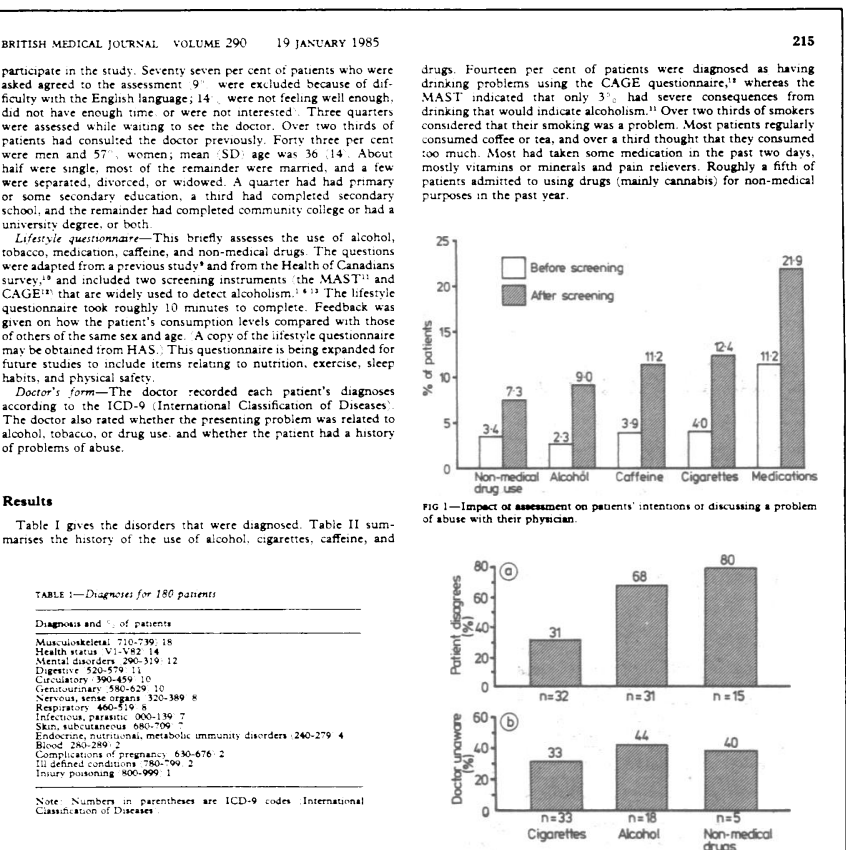

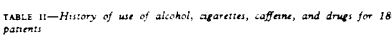

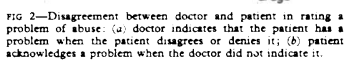
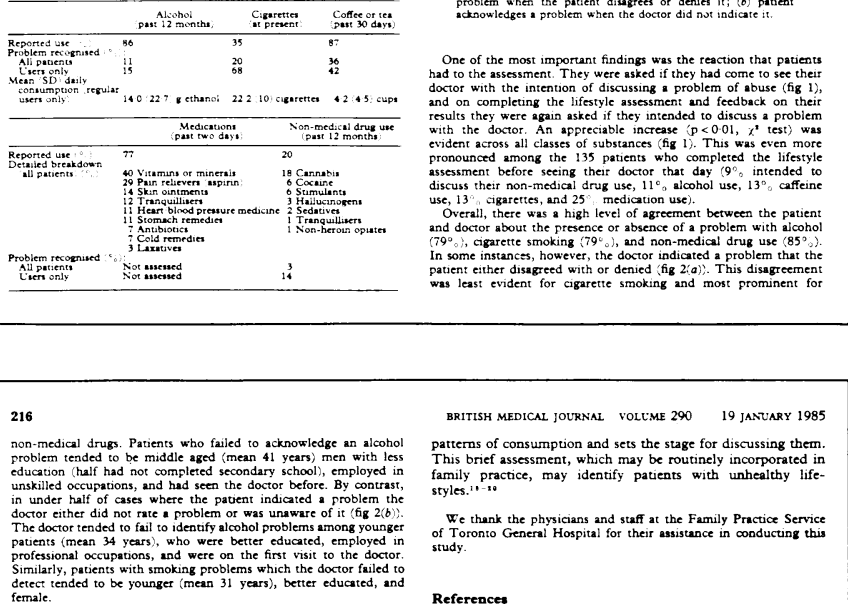

Discussion

Our findings show that a brief assessment of the use of
alcohol, cigarettes, caffeine, and drugs is feasible in a bus alcohol, cigaretes, caffeine, and drugs is feasible in a busy
practice, and that an appreciable number of patients may be
identified whe are concermed about their consumption. The lifestyle questionnaire may be administered in 10 minutes by
practice nurse, or it may be completed by patients while they
wait to see the doctor, or it may be conducted efficiently using 2 microcomputer."
The doctors in this study tended not to detect problems with The doctors in this study tended not ro detect problems with
new patients who had "positive" social characterisics - for
example, young, better educared professionals. On the other hand, they were more
patients with "negative" social characteristics-less education, unskilled occupations. This is consistent with the findings of
other studies of patient characteristics that elicit negative

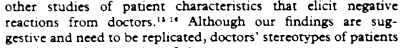
may hinder the detection of abuse. in a twofold or threefold
Being asked questions resslted
increase in the patitents' intentions of discussing abuse with the Being asked questions resulted in a twofold or threefold
increase in the patients' intentions of discussisg abbuse with the
doctor. This " "priming" effect was particularly evident among doctor. This "priming" effect was particularly evident among
patients who underwent the lifestyle assessment before secing
their doctor. The results of other studies have shown that patients
a the

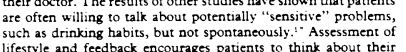

BRITISH MEDICAL JOURNAL VOLLME $290 \quad 19$ JANUARY 1985 patterers of consumption and sets the stage for discussing them.
This brief assessment, which may be routinely ynowrporated in
family practice, may identify patients with unhealthy lifestyles."- -10 We thank the physicians and staff at the Family Practice Service
of Toronnt General Hospital for their assistance in conducucing this
study.

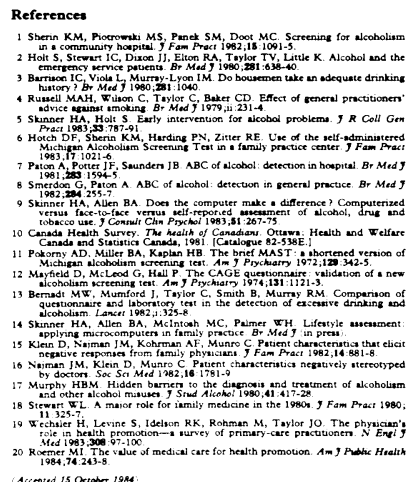

100 YEARS AGO

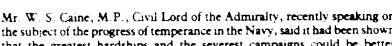

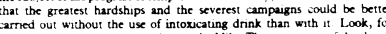

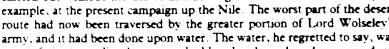

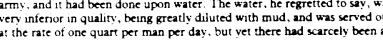

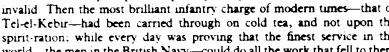

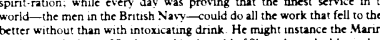

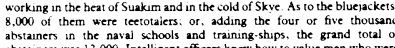

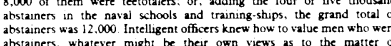

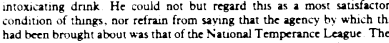

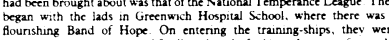

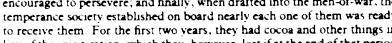

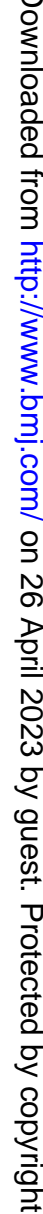

